\title{
ERRATUM
}

\author{
M. J. Faville · A. C. Vecchies $\cdot$ M. Schreiber \\ M. C. Drayton · L. J. Hughes · E. S. Jones \\ K. M. Guthridge $\cdot$ K. F. Smith $\cdot$ T. Sawbridge \\ G. C. Spangenberg · G. T. Bryan · J. W. Forster
}

\section{Functionally associated molecular genetic marker map construction in perennial ryegrass (Lolium perenne L.)}

Published online: 18 February 2005

(C) Springer-Verlag 2005

\section{Theor Appl Genet (2004) 110:12-32}

In Table 6, the sequences of individual forward and reverse amplification primers for selected EST-SSR loci were merged into one line in the final column. The correct version is printed below.
The online version of the original article can be found at http:// dx.doi.org/10.1007/s00122-004-1785-7

M. J. Faville · G. T. Bryan

Grasslands Research Centre, AgResearch Ltd.,

Private Bag 11008, Palmerston North, New Zealand

A. C. Vecchies · M. C. Drayton · L. J. Hughes

E. S. Jones · K. M. Guthridge $\cdot$ T. Sawbridge

G. C. Spangenberg · J. W. Forster

Primary Industries Research Victoria,

Plant Biotechnology Centre, La Trobe University,

Bundoora, VIC, 3086, Australia

A. C. Vecchies - M. C. Drayton - L. J. Hughes - E. S. Jones

K. M. Guthridge - K. F. Smith · T. Sawbridge

G. C. Spangenberg · J. W. Forster $(\bowtie)$

Molecular Plant Breeding Cooperative

Research Centre, Australia

E-mail: john.forster@dpi.vic.gov.au

Tel: $+61-3-94795645$

Fax: $+61-3-94793618$

M. Schreiber

AgResearch Limited, School of Biological Sciences,

University of Auckland, Private Bag

92019, Auckland, New Zealand

K. F. Smith

Primary Industries Research Victoria, Hamilton Centre,

Private Bag 105, Hamilton, VIC, 3300, Australia
Present address: L. J. Hughes

School of Biological Sciences and Biotechnology,

Division of Science and Engineering,

Murdoch University, South Street, Murdoch, WA,

6150, Australia

Present address: E. S. Jones

Crop Genetics Research and Development,

Pioneer Hi-Bred International,

7300 NW 62nd Avenue, Johnston,

IA 50131-1004, USA

Present address: K. M. Guthridge

Cell Cycle and Development Laboratory,

Peter MacCallum Cancer Centre,

St. Andrew's Place, East Melbourne, VIC,

3002, Australia

Present address: T. Sawbridge

Molecular Bioscience Technologies,

Department of Primary Industries and Fisheries,

Queensland Biosciences Precinct,

The University of Queensland,

Level 6 North Tower, 306 Carmody Road,

St. Lucia, 4072, Australia 
Table 6 Primer sequences and locus map position data for 20 EST-SSR markers mapped in the $\mathrm{F}_{1}\left(\mathrm{NA}_{6} \times \mathrm{AU}_{6}\right)$ population. The top sequence of each primer pair is the forward primer, and the bottom sequence is the reverse primer

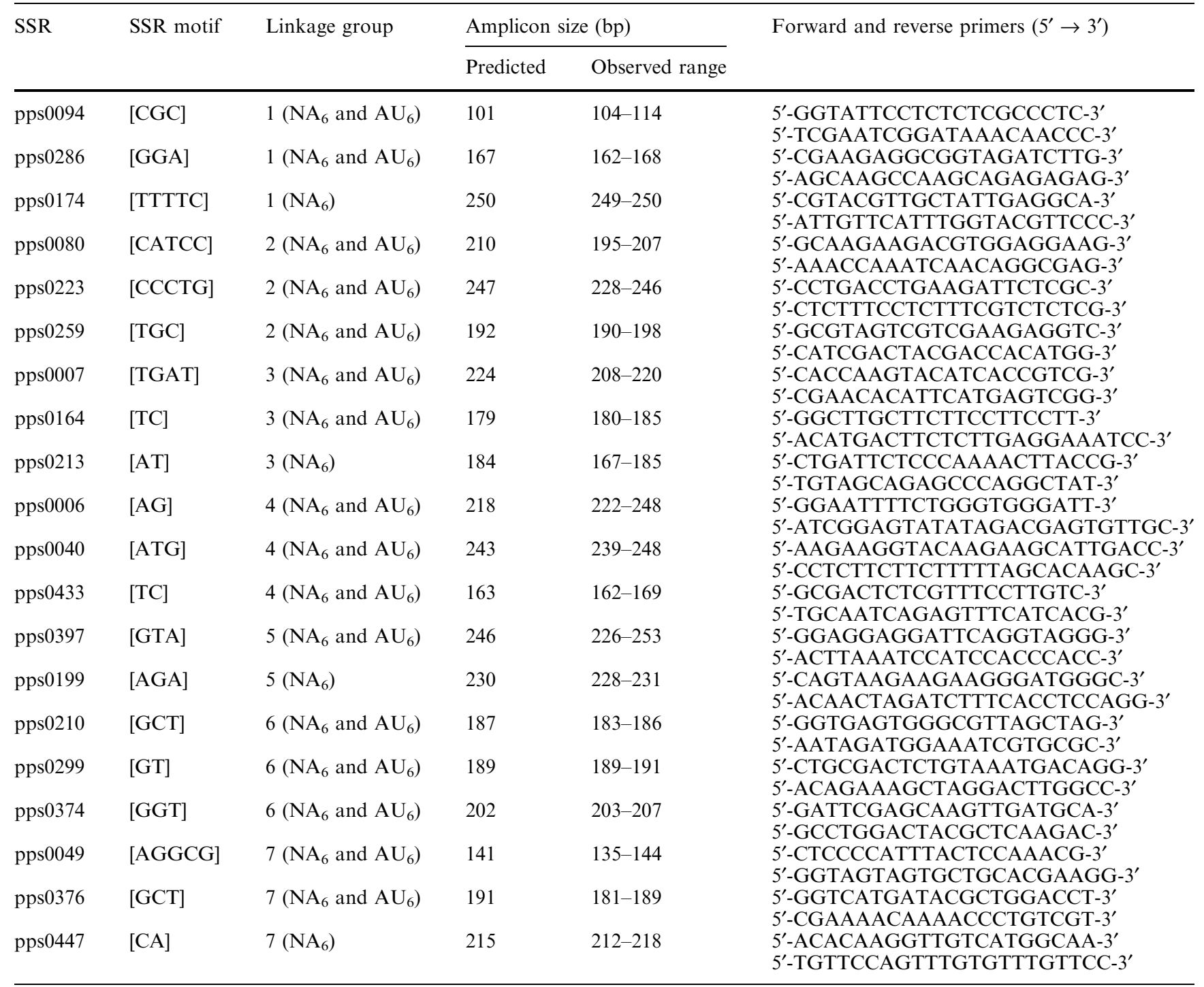

